\title{
Nicotine smoking is associated with impaired cognitive performance in Pakistani young people
}

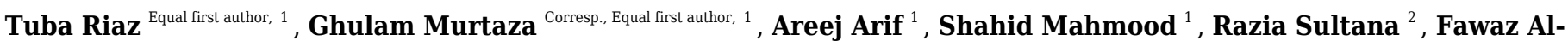 \\ Hussain ${ }^{3}$, Shahid Bashir ${ }^{4}$ \\ 1 Department of Zoology, University of Gujrat, Gujrat, Pakistan \\ 2 Institute of Agricultural Sciences, University of the Punjab, Lahore, Pakistan \\ 3 Department of Neurology, College of Medicine, King Saud University, Riyadh, Saudi Arabia \\ 4 Neuroscience Center, King Fahad Specialist Hospital, Dammam, Saudi Arabia \\ Corresponding Author: Ghulam Murtaza \\ Email address: drghulam.murtaza@uog.edu.pk
}

Nicotine smoking is the most common mode of tobacco smoking among young people. It affects the areas of the brain associated with memory, attention, and learning. This study has investigated the effect of nicotine smoking on cognitive performance. One hundred male volunteers (50 nicotine smokers and 50 nonsmokers) aged 18-30 years with similar socioeconomic backgrounds were recruited for this study. Clinical history of participants was obtained using a questionnaire. Their brain health and handedness were determined using the Mini Mental State Examination (MMSE) and the Edinburgh Handedness Inventory $(\mathrm{EHI})$, respectively. The dependent variables examined in the study were attentionswitching tasks (AST), pattern recognition memory (PRM), and choice reaction time (CRT). These parameters were assessed using the Cambridge Neuropsychological Automated Battery (CANTAB). The average ages of participating smokers and nonsmokers were 24.02 \pm 3.41 years (mean \pm standard deviation) and $22.68 \pm 1.87$ years, respectively. MMSE and EHI scores of smokers were $28.42 \pm 1.09$ and $99.75 \pm 1.77$, respectively; for nonsmokers, these scores were $28.54 \pm 1.34$ and $98 \pm 1.91$, respectively. The mean score for AST correct latency/delay was significantly higher $(p=0.050)$ in smokers $(620.26 \pm$ $142.03)$ than in nonsmokers $(570.11 \pm 108.39)$. The percentage of correct AST trials was significantly higher $(p=0.000)$ in nonsmokers $(96.95 \pm 2.18)$ than in smokers $(83.75 \pm$ 11.22). The PRM percent correct were significantly higher $(p=0.000)$ of nonsmokers (93.42 \pm 8.34$)$ than of smokers $(79.75 \pm 13.44)$. The mean correct latency for CRT was significantly higher $(p=0.009)$ in smokers $(509.87 \pm 129.83)$ than in nonsmokers $(455.20$ $\pm 65.73)$. From this data, it can be concluded that nicotine smoking is linked with impaired cognitive functions in smokers. 
1 Nicotine smoking is associated with impaired cognitive performance in Pakistani young 2 people

3 Tuba Riaz ${ }^{1}$, Ghulam Murtaza ${ }^{1 *}$, Areej Arif ${ }^{1}$, Shahid Mahmood ${ }^{1}$, Razia Sultana ${ }^{2}$, Fawaz Al4 Hussain $^{3}$, Shahid Bashir ${ }^{4}$

6 Tuba Riaz and Ghulam Murtaza contributed equally to this study.

$8{ }^{1}$ Department of Zoology, University of Gujrat, Gujrat, Pakistan

9 Institute of Agricultural Sciences, University of the Punjab, Lahore, Pakistan

$10{ }^{3}$ Department of Neurology, College of Medicine, King Saud University, Riyadh, Saudi Arabia

$11{ }^{4}$ Neuroscience Center, King Fahad Specialist Hospital, Dammam, Saudi Arabia

14 Ghulam Murtaza: drghulam.murtaza@uog.edu.pk

15 Tuba Riaz: 17111714-014@uog.edu.pk

16 Areej Arif: areejarif125@gmail.com

Shahid Mahmood: shahid.mahmood@uog.edu.pk

18 Razia Sultana:

raziam25@yahoo.com

Fawaz Al-Hussain: faalhussain@ksu.edu.sa

Shahid Bashir:

Shahid.bashir@kfsh.med.sa

21

Short Title: Smoking and cognitive performance

\section{Corresponding Author ${ }^{*}$}

Dr. Ghulam Murtaza

27 Gujrat

E-Mail: drghulam.murtaza@uog.edu.pk 


\section{Abstract}

30

$47 \pm 13.44)$. The mean correct latency for CRT was significantly higher $(p=0.009)$ in smokers

$48(509.87 \pm 129.83)$ than in nonsmokers $(455.20 \pm 65.73)$. From this data, it can be concluded that

Nicotine smoking is the most common mode of tobacco smoking among young people. It affects the areas of the brain associated with memory, attention, and learning. This study has investigated the effect of nicotine smoking on cognitive performance. One hundred male volunteers (50 nicotine smokers and 50 nonsmokers) aged 18-30 years with similar socioeconomic backgrounds were recruited for this study. Clinical history of participants was obtained using a questionnaire. Their brain health and handedness were determined using the Mini Mental State Examination (MMSE) and the Edinburgh Handedness Inventory (EHI), respectively. The dependent variables examined in the study were attention-switching tasks (AST), pattern recognition memory (PRM), and choice reaction time (CRT). These parameters were assessed using the Cambridge Neuropsychological Automated Battery (CANTAB). The average ages of participating smokers and nonsmokers were $24.02 \pm 3.41$ years (mean \pm standard deviation) and $22.68 \pm 1.87$ years, respectively. MMSE and EHI scores of smokers were 28.42 \pm 1.09 and $99.75 \pm 1.77$, respectively; for nonsmokers, these scores were $28.54 \pm 1.34$ and $98 \pm 1.91$, respectively. The mean score for AST correct latency/delay was significantly higher $(p=0.050)$ in smokers $(620.26 \pm 142.03)$ than in nonsmokers $(570.11 \pm 108.39)$. The percentage of correct AST trials was significantly higher $(p=0.000)$ in nonsmokers $(96.95 \pm 2.18)$ than in smokers $(83.75 \pm 11.22)$. The PRM percent correct were significantly higher $(p=0.000)$ of nonsmokers $(93.42 \pm 8.34)$ than of smokers $(79.75$ nicotine smoking is linked with impaired cognitive functions in smokers. 
50 Key Words: Nicotine smoking, attention switching task (AST), pattern recognition memory

51 (PRM), choice reaction time (CRT), Cambridge neuropsychological automated battery

52 (CANTAB).

53

54

55

56

57

58

59

60

61

62

63

64

65

66

67

68

69

70

71

72

PeerJ reviewing PDF | (2020:09:52950:3:0:NEW 13 Apr 2021) 


\section{Introduction}

A cigarette is well-engineered device to inhale smoke deep into the lungs (Benjamin, 2011; Service et al., 2010). In the USA, in 2016, prevalence of cigarette smoking was $17.5 \%$ and $13.5 \%$ among males and females, respectively (Jamal et al., 2018). In Pakistan, age-standardized prevalence of tobacco consumption is $13.4 \%$ (Basit, Younus, Waris, \& Fawwad, 2020). According to the World Health Organization (WHO), tobacco use is the leading cause of poverty, disease, and death worldwide (WHO 2020). It causes more than eight million deaths per year, 1.2 million deaths occur due to second-hand smoke (WHO 2020). These possible consequences of cigarette smoking demonstrate its dangers, yet it is practiced by a considerable number of individuals (Benowitz, 2010). Nicotine dependence is considered a "substance use disorder" and is listed in the fourth edition of the Diagnostic and Statistical Manual of Mental Disorders (DSM-IV) (1994) and its text revised edition the DSM IV TR (2000) (Association, 2000; First, 1994). Cigarette smokers perceive themselves to enjoy more at parties while smoking and experience more relaxation (Klein, Sterk, \& Elifson, 2014). Another reason smokers continue to smoke is that they may experience impaired working memory, attention, and concentration when they try to quit (Harrison, Coppola, \& McKee, 2009; McClernon et al., 2008).

The impact of nicotine on cognitive performance is an interesting and active area of research. Nicotine administration causes release of the neurotransmitter acetylcholine (Reid, Lloyd, \& Rao, 1999), which is associated with increase in attention (Herrero et al., 2008). Nicotine has significant positive effects on attention, memory, and motor abilities (Heishman, Kleykamp, \& Singleton, 2010). Alertness and attention are found better in mild smokers as compared to nonsmokers (Vajravelu, Gnanadurai, Krishnan, \& Ayyavoo, 2015). On the other hand, a prospective questionnaire study conducted in subjects recruited from Minnesota state of the U.S has described 
96

97

negative association between tobacco use and cognitive function (Ge et al., 2019). Recent studies have also demonstrated an association between smoking and cognitive impairment in Saudi (Bashir et al., 2017; Bashir, Murtaza, Meo, \& Al-Masri, 2020) and in Chinese (Xia et al., 2019) adult populations. For clear demonstration of association between nicotine smoking and cognitive function, the Cambridge Neuropsychological Test Automated Battery (CANTAB) was used in this study. The CANTAB is a standard software used to assess cognitive functions such as attention, memory, and decision-making ability (Chamberlain, Odlaug, Schreiber, \& Grant, 2012; Karlsen et al., 2020). As, it is a computer-based test, it requires less time for completion. Results are not affected by tiredness of participants (Chamberlain et al., 2012; Karlsen et al., 2020). Moreover, it provides more accurate results as compared to paper-based cognitive assessment tests, particularly on tasks that require time counting and may involve response delay, such as attention switching task (AST).

Response to drugs varies in different populations (Edwards \& Aronson, 2000). Previously, effect of nicotine smoking on cognitive function has been investigated in Chinese population (Xia et al., 2019), the US population (Chamberlain et al., 2012), and Saudi population (Bashir et al., 2017; Bashir et al., 2020) using CANTAB. Impact of nicotine smoking on cognitive performance remains controversial (Chamberlain et al., 2011). It would be of great interest to investigate the effect of nicotine smoking on cognitive function in other populations. Our ultimate aim was to investigate the association between nicotine smoking and cognitive performance in Pakistani male young population in the hope to clarify the role of nicotine on cognitive performance.

\section{Materials and Methods}

This cross-sectional study was conducted in the Department of Zoology, University of Gujrat, Punjab, Pakistan from February to May 2019. Socio-demographic and -economic status-matched 
119 design was employed to assess the association between cigarette smokers and nonsmokers

120 cognitive function.

\section{Selection of Subjects}

122 Selection of participants was based on their volunteer participation. Subjects were asked about

123 their social, demographic, economic, and health characters through face-to-face interviews. Socio-

124 demographic and -economic variables included age, gender (male), marital status (married and 125 single), education (subjects were either pursuing their education after completing 14 years of 126 education or have completed 16 years of education with no further study) and employment 127 (unemployed and employed; employed subjects had monthly income less than 560 U.S Dollars.

128 Subjects who had smoked at least five cigarettes per day for the last year were assigned to the 129 smoking group. Nonsmokers (control group) had never smoked a cigarette in the last 30 days. 130 Although, they might have used it (tobacco cigarette, e-cigarette, and waterpipe) in social 131 gatherings in the past but never smoked on regular basis. Hundred male participants were recruited 132 for this study. Each group of smokers and nonsmokers consisted of 50 individuals aged $24.02 \pm$ 1333.41 (mean \pm SD) years and $22.68 \pm 1.87$ years, respectively. Participants' ages ranged from 18 to 13430 years. The sample size of the present study was based on the previous studies which 135 demonstrated significant association between smoking and cognitive function impairment; 136 smokers $\mathrm{n}=22$, nonsmokers $\mathrm{n}=30$ (Bashir et al., 2017), nicotine smokers, shisha smokers, and 137 nonsmokers $n=25$ each (Bashir et al., 2020). Thus, we planned to recruit 100 participants (smokers 138 and nonsmokers $\mathrm{n}=50$ each), which would be needed to investigate the association between 139 smoking and cognitive function. All the participants in this study were male as it was difficult to 140 recruit female smokers for research due to cultural reasons. Moreover, smoking prevalence is 141 higher in men than women in Pakistan (Basit et al., 2020). 
142 Exclusion Criteria: Individuals addicted to alcohol or other addictive substances and suffering

143 from diabetes mellitus, obesity, anemia, obstructive lung diseases, malignance, difficulty in vision,

144 attention, psychiatric problems, seizures, musculo-skeletal disorders and disturbed sleep history

145 were excluded from the study (Bashir et al., 2017; Bashir et al., 2020).

146 Ethical Approval: Verbal consent was obtained from participants for their inclusion in the study.

147 All procedures were conducted according to the Declaration of Helsinki and ethical standards of 148 local Institutional Review Board (IRB), University of Gujrat. Moreover, ethical approval was 149 obtained from IRB prior to starting the study (Ref: UOG/ORIC/2019/326).

\section{Cognitive Function}

151 Mini Mental State Examination (MMSE) (Folstein, Folstein, \& McHugh, 1975) and Edinburg

152 Handedness Inventory (EHI) (Veale, 2014) were used to determine the mental health and dominant 153 hand of participants, respectively.

154 We employed CANTAB research suit software, version 6.0.37 (Cognition, 2008) to perform 155 different tests, which included AST, pattern recognition memory (PRM), and choice reaction time 156 (CRT) to assess cognitive function. The test takes 25 to 30 minutes to complete. During the test, 157 participants sat comfortably in front of computer and pressed the response button. The testing 158 process has been described in detail in a previous study (Bashir et al., 2017).

\section{Attention switching task (AST)}

160 The detail description of the AST has been described in a previous study (Bashir et al., 2020). This 161 test assesses the participant's ability to switch attention between the direction of an arrow and its 162 location on the screen and to ignore task-irrelevant information in the face of interfering or 163 distracting events. It measures the cognitive control processes involved in the prefrontal cortex 164 part of the brain and determines the executive function. In this test, each trial displays a cue at the 
165 top of the screen that indicates to the participant whether they have to press the right or left button 166 according to the "side on which the arrow appears" or the "direction in which the arrow is 167 pointing". Some trials display congruent stimuli (arrow is present on the right side of the screen 168 pointing to the right) whereas other trials display incongruent stimuli, which require a higher 169 cognitive demand (arrow is present on the right side of the screen pointing to the left). AST test 170 outcome measures include response latencies and error scores.

\section{Pattern recognition memory (PRM)}

172 This is a task of visual pattern recognition memory. In this task, a paradigm design for the visual 173 pattern is displayed on the screen to memorize it (Bashir et al., 2020). The visual patterns are not 174 easy to be labelled verbally. Then, the paradigm is displayed again for the second time with pairs.

175 The person has to select the correct pattern that he has already seen. PRM task allows to measure 176 the number and percentage of correct patterns selected. In this test, PRM raw score obtained 177 represents PRM percent correct which indicates the number of correct responses expressed as a 178 percentage.

\section{Choice reaction time (CRT)}

180 CRT measures the reaction time for two stimuli displayed on the computer screen. These stimuli are with two choices either the arrow is present on the left side or right side. Reaction time (ms) is measured when a person presses the button for the left or right side. Using this test, correct and incorrect responses, latency (response speed), and errors of commission and omission (late and early responses) can be assessed.

\section{Statistical analysis}

SPSS software was used to analyze the data. The quantitative data of smokers and nonsmoker 187 groups were compared. As two groups were unrelated, t-test for independence was used for 
188 comparison. Significance among groups was calculated by applying $t$-test for independence. $P$ 189 values $\leq 0.05$ were considered as significant. Mean difference and standard deviation were also 190 calculated and compared in the present study.

\section{Results}

192 The study participants consisted of 100 male volunteers. Demographic data of all participants were 193 collected using a questionnaire. Numbers of participants who had completed 14-16 years 194 education, were married or single, and employed or unemployed were comparable between 195 smokers and nonsmokers. The MMSE score of 24 or more (out of 30) indicates mental stability. 196 Handedness was determined using the EHI to ensure that subjects used their dominant hand to 197 complete all the tests. The MMSE scores of smokers and nonsmokers were $28.42 \pm 1.09$ and 28.54 $198 \pm 1.34$, respectively. The EHI scores of smokers and nonsmokers were $99.75 \pm 1.77$ and $98 \pm 1.91$, 199 respectively (Table 1).

200 The AST congruent cost (mean, correct) and mean AST correct latency (block 7) (switching block) 201 were higher for smokers than for nonsmokers. However, this difference was not significant. The 202 mean AST correct latency (blocks 3, 5) (non-switching blocks) was also higher for smokers $203(574.95 \pm 111.05)$ than for nonsmokers $(501.56 \pm 68.10)$; this difference was significant $(p=$ 204 0.000). The AST switching cost (mean, correct) did not differ significantly between smokers and 205 nonsmokers. The mean AST correct latency was significantly higher $(p=0.050)$ for smokers $206(620.26 \pm 142.03)$ than for nonsmokers $(570.11 \pm 108.39)$. The mean AST correct latency 207 (congruent) and AST correct latency (incongruent) were significantly higher for smokers $(p=$ 208 $0.046, p=0.036$, respectively) than for nonsmokers. The percentage of correct AST trials was 209 significantly higher $(p=0.000)$ for nonsmokers $(96.95 \pm 2.18)$ than for smokers $(83.75 \pm 11.22)$. 
210 The PRM percent correct of smokers were $79.75 \pm 13.44$ and of nonsmokers were 93.42 \pm 8.34 .

211 This difference was also significant $(p=0.000)$.

212 Mean CRT correct latency of smokers $(509.87 \pm 129.83)$ was significantly higher $(p=0.009)$ than

213 that of nonsmokers $(455.20 \pm 65.73)$. The percentage of correct CRT trials was lower for smokers

$214(95.30 \pm 4.09)$ than for nonsmokers $(98.48 \pm 1.64)$; this difference was also significant $(p=0.000)$

215 (Table 2, Figure 1).

216 Discussion

217 The present study examines the effect of nicotine smoking on cognitive function in young people 218 of Gujrat, Punjab, Pakistan. Three functional outcomes - attention, memory, and reaction time-

219 were assessed for participants in the same age group with the same levels of education and 220 socioeconomic status. Our data indicate cognitive impairment in nicotine smokers. A previous 221 study conducted in subjects from British Civil service reported that middle-aged smokers 222 experienced faster age-related decline in cognitive function than nonsmokers (Sabia et al., 2012). 223 In young adult smokers of Minneapolis-St. Paul area, Minnesota, USA, cognitive impairment was 224 demonstrated in different domains such as spatial working memory, sustained attention, executive 225 planning, and spatial working memory (Chamberlain et al., 2012). In recent studies (Bashir et al., 226 2017; Bashir et al., 2020), impairment in attention and PRM was demonstrated in young adult 227 smokers of Saudi Arabia. Thus, our data are in concordance with previous findings (Bashir et al., 228 2017; Bashir et al., 2020).

229 Previous studies have found that cognitive changes occur with normal aging (Harada, Natelson 230 Love, \& Triebel, 2013; Murman, 2015). Since age affects cognitive performance, we selected 231 participants of the same age group for the present study. Research has found that poor 232 socioeconomic status (Raizada \& Kishiyama, 2010; Yang, Martikainen, Silventoinen, \& 
233 Konttinen, 2016) and low levels of education can negatively affect cognitive performance (Lipina

234 \& Posner, 2012) An association between higher levels of education and higher cognitive function

235 has been demonstrated in (Lee, Buring, Cook, \& Grodstein, 2006; Zahodne, Stern, \& Manly,

236 2015). Thus, to avoid any confounding effects of socioeconomic status, we recruited subjects with

237 similar socioeconomic statuses.

238 We observed significant impairment to the cognitive function of smokers. Values of AST mean 239 correct latency and AST mean correct latency congruent and incongruent were significantly higher

240 for smokers than for nonsmokers. These results align with previous studies (Bashir et al., 2017;

241 Bashir et al., 2020) of Saudi young people, where the software (CANTAB) and the parameters;

242 AST and PRM were used for investigation. We also found that PRM percent correct of nonsmokers

243 were significantly higher than of smokers. This was similar to a previous study (Bashir et al.,

244 2017), although the difference in that case was not significant. In another recent study (Bashir et

245 al., 2020), PRM percent correct were higher for smokers as compared to nonsmokers, however

246 results were not significantly different. These results were attributed to preservation of memory

247 functions in smokers (Bashir et al., 2017). However, these differences in results can also be

248 attributed to differences in sample size and the socioeconomic conditions of the sample groups, as

249 age-related cognitive change affects people living under different socioeconomic conditions

250 differently (Weng et al., 2018). A recent study (Xia et al., 2019) examined the effect of nicotine

251 smoking on Chinese population (age 45-46 years) using repeatable battery for the assessment of

252 neuropsychological status (RBANS) and demonstrated lower immediate and delayed memory

253 scores in smokers compared to nonsmokers. We have also found significantly higher CRT latency

254 values for smokers compared to nonsmokers, which suggests impairment in ability to maintain 
255 vigilance and attention for the target stimulus in smokers. To the best of our knowledge, this is the

256 first study that demonstrates the cognitive effect of nicotine smoking using CRT parameters.

257 Our finding that there is an association between smoking and cognitive problems aligns with other

258 studies (Durazzo, Meyerhoff, \& Nixon, 2012; Fried, Watkinson, \& Gray, 2006) in which smokers

259 performed worse than nonsmokers on memory, processing speed, and visuospatial learning tasks

260 assessed using a neurocognitive battery. In this study, we compared the cognitive function of

261 smokers and nonsmokers using CANTAB, which is an automated, neuropsychological battery and

262 may offer unbiased results for different cognitive functions such as attention, learning, memory,

263 and executive functions (Collie et al., 2007; Karlsen et al., 2020; Robbins et al., 1994).

264 The limitations of our study are the small sample size and its cross-sectional design. Our data are

265 from low- to middle-income subjects. High-income subjects, white-collar civil servants, and

266 females were not included in this study. Moreover, this study is from a small area (Gujrat) and

267 does not cover all the areas of Pakistan. Thus, we cannot say that these data are from general

268 population. In our study, smoking behavior and health measures were self-reported. Number of

269 cigarettes smoked in routine reported by smokers may vary. No laboratory test was performed to

270 determine the addiction pattern and health measures in smokers. Larger prospective studies with

271 more detailed assessments are required to identify the true links between smoking and cognitive

272 impairment. In our study, we were unable to recruit female smokers. Moreover, higher smoking

273 prevalence is demonstrated in men as compared to women in Pakistan (Basit et al., 2020).

274 Similarly, in other studies, conducted in Saudi Arabia (Bashir et al., 2017; Bashir et al., 2020) and

275 China (Xia et al., 2019), only male participants were recruited to find the association between

276 nicotine smoking and cognitive function. Another limitation of the present study is that it does not

277 have data of age when smokers started smoking, duration and intensity of cigarette smoking. 


\section{Conclusion}

279 We found that young cigarette smokers experienced significant impairment to cognitive function

280

281

282

283

284

285

286

287

288

289

290

291

292

293

294

295

296

297

298

299

300

301

302

303

304

305

306

307

308

309

310

311

312

313

314

315

compared to nonsmokers. These results suggest that young adults should quit smoking cigarettes.

Cigarette smoking affects cognitive abilities and can trigger demonstrable abnormalities in brain neurocognition.

\section{References}

Association, A. P. (2000). Diagnostic and statistical manual of mental disorders (text revision). Washington, DC: Author.

Bashir, S., Alghamd, F., Alhussien, A., Alohali, M., Alatawi, A., Almusned, T., \& Habib, S. S. Effect of Smoking on Cognitive Functioning in Young Saudi Adults. Med Sci Monit Basic Res, 23, 31-35. doi: 902385 [pii]

$10.12659 / \mathrm{msmbr} .902385$

Bashir, S., Alghamd, F., Alhussien, A., Alohali, M., Alatawi, A., Almusned, T., \& Habib, S. S. (2017). Effect of Smoking on Cognitive Functioning in Young Saudi Adults. Med Sci Monit Basic Res, 23, 31-35. doi: $10.12659 / \mathrm{msmbr} .902385$

Bashir, S., Murtaza, G., Meo, S. A., \& Al-Masri, A. (2020). Effect of Cigarette and Shisha smoking on cognitive functions impairment: A cross sectional study. Pak J Med Sci, 36(5), 1042-1047. doi: 10.12669/pjms.36.5.2251

Basit, A., Younus, B. B., Waris, N., \& Fawwad, A. (2020). Prevalence of tobacco use in urban and rural areas of Pakistan; a sub-study from second National Diabetes Survey of Pakistan (NDSP) 2016 - 2017. Pak J Med Sci, 36(4), 808-815. doi: 10.12669/pjms.36.4.1705

Benjamin, R. M. (2011). Exposure to tobacco smoke causes immediate damage: a report of the Surgeon General. Public Health Rep, 126(2), 158-159. doi: 10.1177/003335491112600202

Benowitz, N. L. (2010). Nicotine addiction. [Research Support, N.I.H., Extramural

Research Support, Non-U.S. Gov't

Review]. N Engl J Med, 362(24), 2295-2303. doi: 10.1056/NEJMra0809890

Chamberlain, S. R., Odlaug, B. L., Schreiber, L. R., \& Grant, J. E. (2012). Association between tobacco smoking and cognitive functioning in young adults. [Research Support, American Recovery and Reinvestment Act

Research Support, N.I.H., Extramural

Research Support, Non-U.S. Gov't]. Am J Addict, 21 Suppl 1, S14-19. doi: 10.1111/j.15210391.2012.00290.x

Chamberlain, S. R., Robbins, T. W., Winder-Rhodes, S., Muller, U., Sahakian, B. J., Blackwell, A. D., \& Barnett, J. H. (2011). Translational approaches to frontostriatal dysfunction in attentiondeficit/hyperactivity disorder using a computerized neuropsychological battery. [Meta-Analysis

Research Support, Non-U.S. Gov't]. Biol Psychiatry, 69(12), 1192-1203. doi: 10.1016/j.biopsych.2010.08.019

Cognition, C. (2008). CANTAB topic: Test-retest reliabilities and detecting reliable change. 
316

Collie, A., Darekar, A., Weissgerber, G., Toh, M. K., Snyder, P. J., Maruff, P., \& Huggins, J. P. (2007). Cognitive testing in early-phase clinical trials: development of a rapid computerized test battery and application in a simulated Phase I study. [Research Support, Non-U.S. Gov't]. Contemp Clin Trials, 28(4), 391-400. doi: 10.1016/j.cct.2006.10.010

Durazzo, T. C., Meyerhoff, D. J., \& Nixon, S. J. (2012). A comprehensive assessment of neurocognition in middle-aged chronic cigarette smokers. [Research Support, N.I.H., Extramural]. Drug Alcohol Depend, 122(1-2), 105-111. doi: 10.1016/j.drugalcdep.2011.09.019

Edwards, I. R., \& Aronson, J. K. (2000). Adverse drug reactions: definitions, diagnosis, and management. Lancet, 356(9237), 1255-1259. doi: 10.1016/S0140-6736(00)02799-9

First, M. B. (1994). Diagnostic and Statistical Manual of Mental Disorders: DSM-IV: American psychiatric publishing.

Folstein, M. F., Folstein, S. E., \& McHugh, P. R. (1975). "Mini-mental state". A practical method for grading the cognitive state of patients for the clinician. J Psychiatr Res, 12(3), 189-198. doi: 10.1016/00223956(75)90026-6

Fried, P. A., Watkinson, B., \& Gray, R. (2006). Neurocognitive consequences of cigarette smoking in young adults--a comparison with pre-drug performance. Neurotoxicol Teratol, 28(4), 517-525. doi: S0892-0362(06)00079-1 [pii]

10.1016/j.ntt.2006.06.003

Ge, L., D'Souza, R. S., Oh, T., Vincent, A., Mohabbat, A. B., Eldrige, J., . . Mauck, W. D. (2019). Tobacco Use in Fibromyalgia Is Associated With Cognitive Dysfunction: A Prospective Questionnaire Study. Mayo Clin Proc Innov Qual Outcomes, 3(1), 78-85. doi: 10.1016/j.mayocpiqo.2018.12.002

Harada, C. N., Natelson Love, M. C., \& Triebel, K. L. (2013). Normal cognitive aging. [Research Support, N.I.H., Extramural

Research Support, Non-U.S. Gov't

Review]. Clin Geriatr Med, 29(4), 737-752. doi: 10.1016/j.cger.2013.07.002

Harrison, E. L., Coppola, S., \& McKee, S. A. (2009). Nicotine deprivation and trait impulsivity affect smokers' performance on cognitive tasks of inhibition and attention. Exp Clin Psychopharmacol, 17(2), 9198. doi: 2009-04252-007 [pii]

$10.1037 / \mathrm{a} 0015657$

Heishman, S. J., Kleykamp, B. A., \& Singleton, E. G. (2010). Meta-analysis of the acute effects of nicotine and smoking on human performance. [Meta-Analysis

Research Support, N.I.H., Extramural

Research Support, N.I.H., Intramural]. Psychopharmacology (Berl), 210(4), 453-469. doi: 10.1007/s00213010-1848-1

Herrero, J. L., Roberts, M. J., Delicato, L. S., Gieselmann, M. A., Dayan, P., \& Thiele, A. (2008). Acetylcholine contributes through muscarinic receptors to attentional modulation in V1. [Research Support, Non-U.S. Gov't]. Nature, 454(7208), 1110-1114. doi: 10.1038/nature07141

Jamal, A., Phillips, E., Gentzke, A. S., Homa, D. M., Babb, S. D., King, B. A., \& Neff, L. J. (2018). Current Cigarette Smoking Among Adults - United States, 2016. MMWR Morb Mortal Wkly Rep, 67(2), 5359. doi: 10.15585/mmwr.mm6702a1

Karlsen, R. H., Karr, J. E., Saksvik, S. B., Lundervold, A. J., Hjemdal, O., Olsen, A., . . Skandsen, T. (2020). Examining 3-month test-retest reliability and reliable change using the Cambridge Neuropsychological Test Automated Battery. Appl Neuropsychol Adult, 1-9. doi: 10.1080/23279095.2020.1722126

Peer) reviewing PDF | (2020:09:52950:3:0:NEW 13 Apr 2021) 
400

401

402

403

404

Klein, H., Sterk, C. E., \& Elifson, K. W. (2014). Smoke and Mirrors: The Perceived Benefits of Continued Tobacco use Among Current Smokers. Health Psychol Res, 2(2), 1519. doi: 10.4081/hpr.2014.1519

Lee, S., Buring, J. E., Cook, N. R., \& Grodstein, F. (2006). The relation of education and income to cognitive function among professional women. [Research Support, N.I.H., Extramural]. Neuroepidemiology, 26(2), 93-101. doi: 10.1159/000090254

Lipina, S. J., \& Posner, M. I. (2012). The impact of poverty on the development of brain networks. Front Hum Neurosci, 6, 238. doi: 10.3389/fnhum.2012.00238

McClernon, F. J., Kollins, S. H., Lutz, A. M., Fitzgerald, D. P., Murray, D. W., Redman, C., \& Rose, J. E. (2008). Effects of smoking abstinence on adult smokers with and without attention deficit hyperactivity disorder: results of a preliminary study. Psychopharmacology (Berl), 197(1), 95-105. doi: 10.1007/s00213-007-1009-3

Murman, D. L. (2015). The Impact of Age on Cognition. Semin Hear, 36(3), 111-121. doi: 10.1055/s-00351555115

Raizada, R. D., \& Kishiyama, M. M. (2010). Effects of socioeconomic status on brain development, and how cognitive neuroscience may contribute to levelling the playing field. Front Hum Neurosci, 4, 3. doi: 10.3389/neuro.09.003.2010

Reid, R. T., Lloyd, G. K., \& Rao, T. S. (1999). Pharmacological characterization of nicotine-induced acetylcholine release in the rat hippocampus in vivo: evidence for a permissive dopamine synapse. Br J Pharmacol, 127(6), 1486-1494. doi: 10.1038/sj.bjp.0702683

Robbins, T. W., James, M., Owen, A. M., Sahakian, B. J., Mclnnes, L., \& Rabbitt, P. (1994). Cambridge Neuropsychological Test Automated Battery (CANTAB): a factor analytic study of a large sample of normal elderly volunteers. [Research Support, Non-U.S. Gov't]. Dementia, 5(5), 266-281. doi: 10.1159/000106735

Sabia, S., Elbaz, A., Dugravot, A., Head, J., Shipley, M., Hagger-Johnson, G., . . Singh-Manoux, A. (2012). Impact of smoking on cognitive decline in early old age: the Whitehall II cohort study. [Comparative Study

Research Support, N.I.H., Extramural

Research Support, Non-U.S. Gov't]. Arch Gen Psychiatry, 69(6), 627-635. doi: 10.1001/archgenpsychiatry.2011.2016

Service, U. S. P. H., General, U. S. P. H. S. O. o. t. S., Health, U. s. D. o., Staff, H. S., Prevention, N. C. f. C. D., Smoking, H. P. O. O., . . . Prevention. (2010). How tobacco smoke causes disease: the biology and behavioral basis for smoking-attributable disease: a report of the Surgeon General: US Government Printing Office.

Vajravelu, H. R., Gnanadurai, T. K., Krishnan, P., \& Ayyavoo, S. (2015). Impact of Quantified Smoking Status on Cognition in Young Adults. J Clin Diagn Res, 9(12), CC01-03. doi: $10.7860 / J C D R / 2015 / 16444.6867$

Veale, J. F. (2014). Edinburgh Handedness Inventory - Short Form: a revised version based on confirmatory factor analysis. [Research Support, Non-U.S. Gov't]. Laterality, 19(2), 164-177. doi: 10.1080/1357650X.2013.783045

Weng, P. H., Chen, J. H., Chiou, J. M., Tu, Y. K., Chen, T. F., Chiu, M. J., . . Chen, Y. C. (2018). The effect of lifestyle on late-life cognitive change under different socioeconomic status. [Research Support, Non-U.S. Gov't]. PLoS One, 13(6), e0197676. doi: 10.1371/journal.pone.0197676

Xia, H., Du, X., Yin, G., Zhang, Y., Li, X., Cai, J., . . Zhang, X. Y. (2019). Effects of smoking on cognition and BDNF levels in a male Chinese population: relationship with BDNF Val66Met polymorphism. [Research Support, Non-U.S. Gov't]. Sci Rep, 9(1), 217. doi: 10.1038/s41598-018-36419-8

Peer) reviewing PDF | (2020:09:52950:3:0:NEW 13 Apr 2021) 
405

406

407

408

409

410

411

412

413

\section{4}

415

416

417

418

419

Yang, L., Martikainen, P., Silventoinen, K., \& Konttinen, H. (2016). Association of socioeconomic status and cognitive functioning change among elderly Chinese people. [Research Support, Non-U.S. Gov't]. Age Ageing, 45(5), 674-680. doi: 10.1093/ageing/afw107

Zahodne, L. B., Stern, Y., \& Manly, J. J. (2015). Differing effects of education on cognitive decline in diverse elders with low versus high educational attainment. [Research Support, N.I.H., Extramural]. Neuropsychology, 29(4), 649-657. doi: 10.1037/neu0000141

\section{Figure legends}

\section{Figure 1. Comparison of cognitive functions between smokers and nonsmokers}

$\mathrm{Y}$-axis shows time taken by the participants to respond. $\mathrm{X}$-axis represents different parameters investigated. AST $=$ attention switching task, $\mathrm{CRT}=$ choice reaction time. Latency values are "mean correct". The results from smokers and nonsmokers were compared by independent t-test. The error bar and * represent standard error of the mean (SEM) and significant difference, respectively. 
Table $\mathbf{1}$ (on next page)

Demographic data of smokers and nonsmokers 
1 Table 1. Demographic data of smokers and nonsmokers

\begin{tabular}{|c|c|c|c|}
\hline \multicolumn{2}{|l|}{ Parameters } & \multirow{2}{*}{$\begin{array}{l}\text { Smokers } \\
50\end{array}$} & \multirow{2}{*}{$\begin{array}{l}\text { Nonsmokers } \\
50\end{array}$} \\
\hline Gender & Male & & \\
\hline & Female & 0 & 0 \\
\hline Age (years) & Mean \pm SD & $24.02 \pm 3.41$ & $22.68 \pm 1.87$ \\
\hline Education & Years of education & $14-16$ & $14-16$ \\
\hline \multirow[t]{2}{*}{ Marital status } & Married, No. (\%) & $9(18)$ & $14(28)$ \\
\hline & Single, No. (\%) & $41(82)$ & $36(72)$ \\
\hline \multirow[t]{2}{*}{ Employment status } & Employed, No. (\%) & $25(32)$ & $21(42)$ \\
\hline & Unemployed, No. (\%) & $34(68)$ & $29(58)$ \\
\hline MMSE & Mean \pm SD & $28.42 \pm 1.09$ & $28.54 \pm 1.34$ \\
\hline EHI & Mean \pm SD & $99.75 \pm 1.77$ & $98 \pm 1.91$ \\
\hline
\end{tabular}

$2 \mathrm{MMSE}=$ mini mental state examination, $\mathrm{EHI}=$ Edinburg handedness inventory, $\mathrm{SD}=$ standard 3 deviation 


\section{Table 2 (on next page)}

Comparison of cognitive functions (AST, PRM, and CRT) between smokers and nonsmokers 
1 Table 2. Comparison of cognitive functions (AST, PRM, and CRT) between smokers and 2 nonsmokers

\begin{tabular}{|l|l|l|l|}
\hline Parameters & $\begin{array}{l}\text { Smokers } \\
(\text { Mean } \pm \text { SD) }\end{array}$ & $\begin{array}{l}\text { Nonsmokers } \\
(\text { Mean } \pm \text { SD })\end{array}$ & $p$-value \\
\hline AST-Congruency cost & $76.00 \pm 57.49$ & $65.37 \pm 40.82$ & 0.289 \\
\hline $\begin{array}{l}\text { AST-Latency (blocks 3,5) [non- } \\
\text { switching blocks] }\end{array}$ & $574.95 \pm 111.05$ & $501.56 \pm 68.10$ & 0.000 \\
\hline $\begin{array}{l}\text { AST-Latency (block 7) [switching } \\
\text { block] }\end{array}$ & $669.96 \pm 208.13$ & $640.94 \pm 167.21$ & 0.444 \\
\hline AST-Switching cost & $95.01 \pm 166.39$ & $139.37 \pm 130.21$ & 0.141 \\
\hline AST-Latency & $620.26 \pm 142.03$ & $570.11 \pm 108.39$ & 0.050 \\
\hline AST-Latency (congruent) & $586.50 \pm 132.46$ & $538.36 \pm 104.00$ & 0.046 \\
\hline AST-Latency (incongruent) & $662.50 \pm 157.44$ & $603.72 \pm 116.56$ & 0.036 \\
\hline AST-Percent correct trials & $83.75 \pm 11.22$ & $96.95 \pm 2.18$ & 0.000 \\
\hline PRM- Percent correct & $79.75 \pm 13.44$ & $93.42 \pm 8.34$ & 0.000 \\
\hline CRT-Latency & $509.87 \pm 129.83$ & $455.20 \pm 65.73$ & 0.009 \\
\hline CRT-Percent correct trials & $95.30 \pm 4.09$ & $98.48 \pm 1.64$ & 0.000 \\
\hline
\end{tabular}

3 PRM-Percent correct are the number of correct responses, expressed as a percentage. AST = 4 attention switching task, $\mathrm{PRM}=$ pattern recognition memory, $\mathrm{CRT}=$ choice reaction time, $\mathrm{SD}=$ 5 standard deviation. Significance among groups was calculated by applying $t$-test for independence. $6 \quad P$-values $\leq 0.05$ were considered as statistically significant. 


\section{Figure 1}

Comparison of cognitive functions between smokers and nonsmokers

Y-axis shows time taken by the participants to respond. X-axis represents different

parameters investigated. AST $=$ attention switching task, CRT $=$ choice reaction time .

Latency values are "mean correct". The results from smokers and nonsmokers were compared by independent t-test. The error bar and * represent standard error of the mean (SEM) and significant difference, respectively.

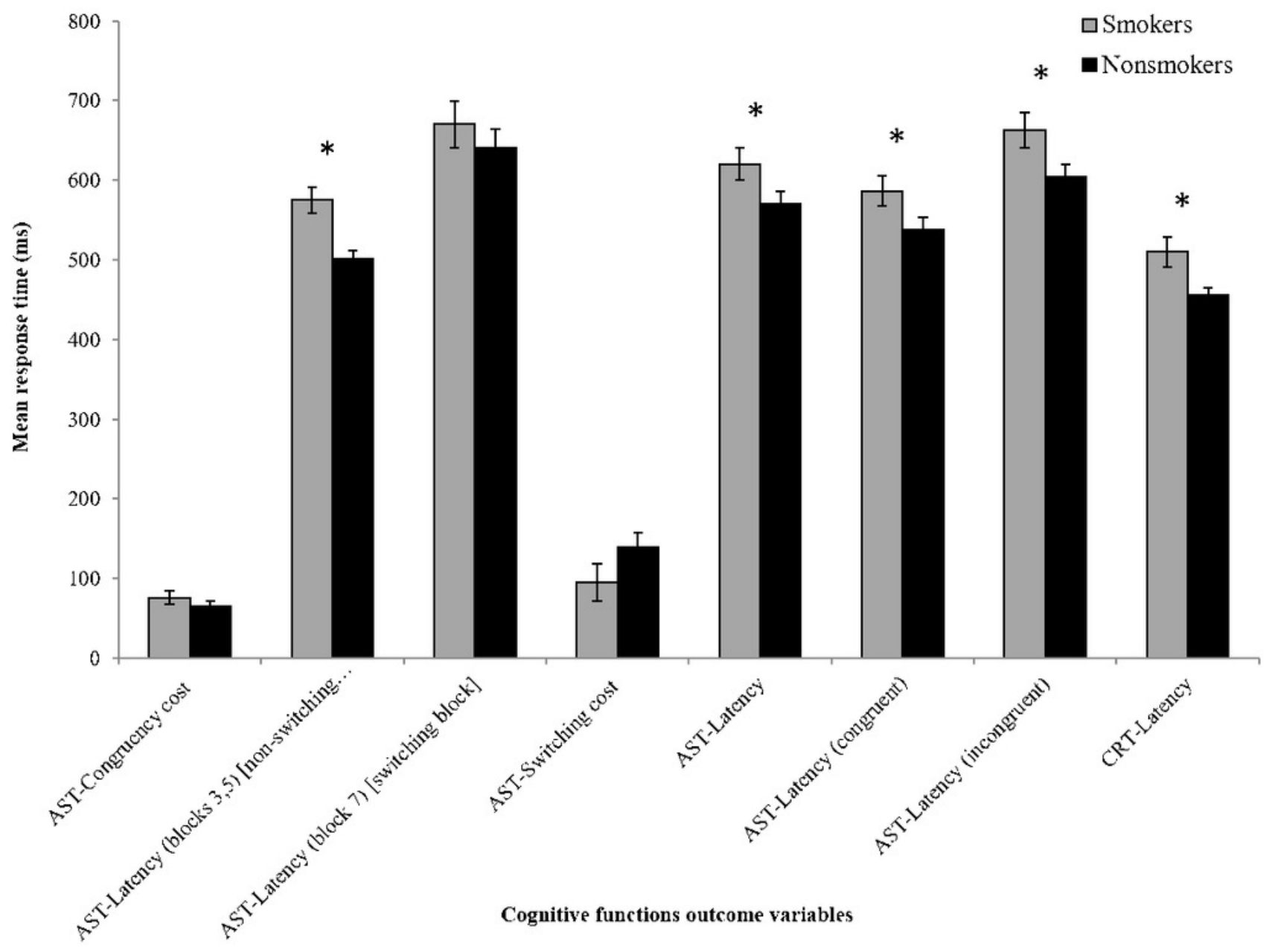

